\title{
Precarious success and the conspiracy of reflexivity: Questioning the 'habitus transformation' of working-class students at elite universities
}

\begin{abstract}
Some authors argue that access to elite universities can bring about a 'habitus transformation' for working-class students, however in this paper, based on a three-year life history study, it is suggested that the transformative effects of the elite university experience come about in relation to and constrained by the working-class habitus. Working-class students tend to choose the strategy of 'compartmentalising' to manage their experience of university - engaging primarily academically and sideling the social aspects of university life. This paper offers a very complex account of such compartmentalising, in which the lack of appropriate capitals, emotional injuries, habitual dispositions and the application of instrumental rationality are fused together to make up the university experience for working-class students. The analysis demonstrates the 'conspiracy' of reflexivity. Reflexivity does not necessarily bring changes in and challenges to an existing habitus; rather reflexivity conspires with and tends to reinforce it. This demonstrates the continuing role of habitus in maintaining class domination in elite settings and raises questions about the effects and effectiveness of the widening participation agenda in HE.
\end{abstract}

Keywords: 'habitus transformation'; reflexivity and habitus; college experience; working-class students at elite universities; meritocracy; upward social mobility

Word count: 7,984 words (including the abstract, references and footnotes) 


\section{Introduction: to what extent is the elite university experience transformative to}

working-class survivors?

Social justice and upward social mobility are at the top of the education policy agenda in many societies and yet social stratification and social inequalities in education persist and are intensifying worldwide (e.g., Liu, Green, \& Pensiero 2016; Shavit \& Blossfeld, 1993). One aspect of this intensification, as a response to the massification of $\mathrm{HE}$, is the increasingly complex stratification of $\mathrm{HE}$ institutions and concomitant shift in focus of upper and middle-class families from managing their domination of higher education generally to their domination of elite higher education institutions. In an intensified global war for top talent in competitive industries (Brown, 2009), the possibility of gaining entry to the global labour market, and for working-class students to achieve upward social mobility, depends heavily on obtaining a degree from an elite university. A number of studies have addressed the unequal access of social classes to elite universities (e.g., Bourdieu \& Passeron, 1990; Bourdieu, 1996) and have demonstrated the various forms of class domination that need to be overcome by working-class students in order to gain entry into such universities.

Further, a few authors have turned the focus to the 'working-class survivors' who do succeed in gaining a place at elite universities against all the odds (e.g., Lehmann, 2013; Li, 2013; Reay, Crozier, \& Clayton, 2009). Some of these studies document the 'transformative' experience of working-class students at elite universities (e.g., Aries \& Seider, 2005; Granfield, 1991; Lehmann, 2013). That is, being exposed to an entirely new cultural setting, albeit having experienced a sense of 
'habitus dislocation' upon arrival to university, many of these working-class students are reported to have coped with their initial discomforts, inferiorities and difficulties by adaptation and self-transformation. They gradually change their speech, attire, tastes, and lifestyle and as they accumulate forms of middle-class capital, they acquire 'new priorities, perspectives, values' (Aries \& Seider, 2005, p. 433). These working-class young people, as these studies suggest, feel empowered by the new experiences and life chances that are opened to them (e.g., Aries \& Seider, 2005; Granfield, 1991). In some cases this is described as 'habitus transformation' (Lehmann, 2013; Xie, 2016).

This 'habitus transformation' is partly motivational, driven by the aspirational habitus (Baker, 2005 quoted in Reay et al., 2007) of these working-class high-achievers, in order to actualise the 'real self' (Lawler, 1999, p. 9), to become middle-class. However, this 'habitus transformation' is also forced upon students as they must 'change or die' in relation to the middle class cultural domination of elite universities (Hurst, 2010) and the external pressures and expectations of high-status employers (Granfield, 1991). These transformative effects of elite university experience are especially highlighted by studies that compare working-class student experiences at elite and non-elite universities (Aries \& Seider, 2005; Bathmaker, Ingram, \& Waller, 2013; Reay, Crozier, \& Clayton, 2010).

However, it is important to recognise that these transformative effects are relational and partial rather than absolute and totalising, as they are constrained by and negotiated in relation to a preceding working-class habitus. As Archer and 
Leathwood (2003) comment, for some students "while they wish to go "through university" they want to ensure "university doesn't go through them"' (p. 177-178). Working-class survivors experience elite universities in 'unique working-class ways' (Lehmann, 2009, p. 634) and several researchers note the 'compartmentalising' (Keane, 2011, p. 456; Reay, Crozier, \& Clayton, 2009, p. 1111) tactics of working-class students - they may experience the elite university as a place for a getting good degree and as a paradise for learning but sideline the social aspects of university life. The reasons for this sidelining are complicated. Loyalty to working-class community and values is reported as one factor (Friedman, 2016; Reay, Crozier, \& Clayton, 2009), while a lack of material resources (Aries \& Seider, 2005) and their sense of a lack of appropriate social skills (Li, 2013; Xie, 2016) is another. We will extend those discussions in this paper and offer a more complex account of how working-class students 'compartmentalise' their engagement with and experience of the elite university.

The strategy of compartmentalising, which constrains working-class students achievement of social integration at university, puts their social mobility journey at risk, they may struggle to turn their paper qualifications into real employment opportunities in high status, high income occupations (Stuber, 2011). Much of the policy rhetoric that articulates both 'widening participation' and social mobility agendas in HE fails to address such issues. This paper reports part of a study of a small group of working-class students at elite universities in China. It is based on the analysis of first-hand accounts of their university experience and focuses on the extent 
to which their university experience has transformative effects in relation to their working-class habitus.

The context and the research method: introducing a 'class' perspective to an 'unusual' context

Our study is based on an 'unusual context' in terms of researching class domination the People's Republic of China - where the discourse of class is infrequently addressed, and indeed to a large extent is silent in what is a highly individualistic and meritocratic culture and history. Yet, as will be seen in this paper, this 'unusual' context provides ideal conditions to explore different 'interacting relations between dominance and autonomy' (Giroux, 1983, p. 290) and the complex relationship between meritocracy, reflexivity and class domination.

The Chinese education system appears at face value to be an ideal meritocratic structure with access to and progression through different levels of elite schools for high performing students ('key schools' and 'key universities' in the Chinese terms), and access to high status subjects at university. Entry into these routes is almost entirely based on the student's performance in examinations - mainly the senior secondary school entrance examination and Gaokao (National College Entrance Examination in China). The performance-based system seems to reduce the significance of family capital and role of subjective evaluations like interviews or application documents that have been shown to privilege middle-class students with the 'right' dispositions, capitals and inheritance (Karabel, 2005). The research 
reported here points to the continuing salience of social class in relation to this meritocractic system and we explore the interplay of meritocracy, reflexivity and class domination in the Chinese context.

Clearly, there are issues raised by the introduction of a 'class' perspective into a context in which class discourse is infrequently used. A rural/urban division is more commonly deployed in studies, policies and media reports in China regarding education inequalities and social mobility. Although we are aware of the vast inequalities and disadvantages associated with the rural/urban divide in China, the sole emphasis on rural students in studies and in policy initiatives ${ }^{1}$ to address education inequality neglects the unequal and accumulatively disadvantaged experience of poor students in cities who directly experience the evolving class structure, intensifying social stratification in schools (Lu, 2013) and the shifting strategies of middle-class families to secure their privileges by investing in high-quality international education (Xiang \& Wei, 2009). The emphasis on the rural/urban divide overshadows the other mechanisms in China that produce and reproduce social inequalities. Therefore we introduce a more comprehensive approach to educational and social inequalities in China, that includes the voices of both rural and urban disadvantaged students. This, we argue, captures disadvantage not only in economic terms but also in social and cultural terms and incorporates more long-standing and nuanced ways of understanding 'disadvantage', such as hidden

\footnotetext{
${ }^{1}$ Chinese central government introduced 'Special University Recruitment Programmes for Rural Students' in 2012, to require universities (the four elite universities in our study included) to allocate a recruitment quota specifically for rural students.
} 
injuries of class (Sennett \& Cobb, 1972), emotional politics (Skeggs, 1997), and symbolic violence (Bourdieu, 1990). In this way, we hope to see beyond the rural/urban divide and target a broader range of and less obvious forms of social reproduction in China that produce and reinforce social inequality. The 'class' perspective and the related 'western' concepts and, particularly Bourdieu's theoretical tools, are of relevance and use here. Also, we suggest, the evidence, reflections, dialogues and comparisons generated from class research in China have the potential to develop these theoretical tools further.

However, introducing a foreign perspective into an 'unusual' context is far from being without problems. For example, compared with the counter-school culture associated with working-class culture and shared by working-class parents, which has been reported in studies based on some other national contexts (e.g., Willis, 1977; Jackson \& Marsden, 1962), most working-class families in China put a high value on education and invest financial and emotional support in their children, a commitment which may be influenced by the Confucian tradition (Marginson, 2011). Also, working-class students in our study rarely report conflict in their learner identity with loyalty to their 'working-class culture and community' (see also the findings in Kipnis, 2001; Xie, 2016). Bearing these problems in mind and being aware that much of the originality of our research comes from an 'unusual' context, we choose the approach of 'Informed Grounded Theory' (Thornberg, 2012) to frame our research design, with 'intimate familiarity' (Charmaz, 2014) with the data and the context always prioritised, and theoretical tools only used reflexively, where necessary and 
appropriate, to help us make imaginary connections, establish dialogue with the literature, challenge our 'biases' and enlarge our 'sociological gaze' (Bourdieu \& Wacquant, 1992, p. 36).

Three-rounds of life story interviews were conducted between March 2015 and December 2017 with 17 working-class students at four elite universities in China: Fudan University, Peking University, Shanghai Jiao Tong University and Tsinghua University. The four universities are chosen from the C9 league (a group of nine top universities in China, which are selected to receive the largest amount of government funding in order to build an elite group of world-class universities ${ }^{2}$ ) and they are all located in Beijing and Shanghai, the two biggest cities in China.

Potential participants were recommended by personal contacts at these four universities. After receiving a list of potential participants, they were contacted individually to introduce the research and to confirm their consent for participation. In the first-round interviews, the 17 participants were all final year undergraduate students who had received National Student Loans (needs-based loans) and we checked their parents' occupations, income and education levels, their place of birth and their self-identification in the interviews in order to 'verify' their working-class status. These accounts were also compared with national statistics (e.g., the national average salary level) and with Lu's (2002) analysis of social classes in China (commonly used as the reference to define class positions in sociological studies in China; the working-class occupations include the unemployed, peasants, factory

\footnotetext{
2 According to the Ministry of Education:

http://www.cdgdc.edu.cn/xwyyjsjyxx/xwsytjxx/yxmd/274942.shtml
} 
workers, service workers and small business owners). Our sample includes male and female students and contains a diversity in subjects studied, parental occupations, rural and urban origins and region of orgin. All interviews were conducted in Mandarin by one of the authors, who is Chinese, and each interview lasted one hour or longer. All interviews were recorded, transcribed in Chinese and field notes were taken immediately after. We used constructive grounded theory techniques (Charmaz, 2014; Keane, 2015) to analyse data, building the theoretical framework through initial coding, focused coding, memo writing, map drawing, constant comparisons and theoretical sampling. All the names of respondents used in publications are pseudonyms.

Based on the analysis of our data, we argue in this paper that socialisation at elite universities and in a strong meritocratic environment does not bring about 'habitus transformation' for working-class survivors but rather a reinforcement of their old habitus and the reproduction of their subjection to class domination. This reinforcement takes place even when a high degree of reflexivity is involved. The 'stickiness' of habitus demonstrates the power of class domination and a complex relation between reflexivity and habitus. 


\section{Conspiracy of reflexivity: work to reinforce rather than to challenge the old}

\section{habitus}

Similar to many other studies, our participants experienced a sense of habitus dislocation upon their arrival to university. Xiang He vividly described the struggles and difficulties they experienced:

All the first year I was struggling to fit in. What I say most often now is the environment (that you are born in) determines who you are and the height you can get to. When I first came to university, came to Beijing, I saw many things for the first time in my life. My first year was to learn what others had learnt many years ago. Taking some small examples, I didn’t know what was KFC, I hadn't had fast food before, I didn't know I needed to wear suits on formal occasions, I didn't know the manners when in a conference and so on. I had to learn a lot from zero.

With a lack of relevant cultural capital such as experience of travel and knowledge of dress codes and appropriate manners, as mentioned by Xiang $\mathrm{He}$, everything at university was terrifyingly 'new' and everything about 'being' a student had to be learned from scratch. On the one hand, such students feel pressure as 'fish out of water' in an entirely new world; on the other hand, they feel impelled to invest enormous effort in order to 'fit in' at university. A sense of habitus dislocation is reported by almost every participant in our study with associated senses of inferiority, incompetence, deficit and disadvantage. These are felt in a lack of cultural experiences, but also in the absence of economic resources and social capital on which they can draw. Class identity is sharpened by the struggles they experienced at the initial stages of university. 
The authors of this paper (2018) described the habitus of these working-class high-achievers as a 'divided habitus' (Bourdieu, 1999) in that they are constantly torn between a high-achieving student self, which brings them exceptionality, hope, ambition and superiority, and a working-class self, which reminds them of their normality, frustration and inferiority. At the same time that their class identity and associated sense of social disadvantage is heightened upon the arrival to university, their high-achieving student identity is endangered. The exam performance-orientated skills they employed at school - to work as hard as possible and to devote as much time as they can to exam success - are found inadequate in striving for academic success at university. As Yue $\mathrm{Gu}$ says below, 'exam performance became less important' and 'you should have your own thoughts'. Also, they see, for the first time, a different enactment of the high-achieving student identity - based on accumulating and deploying forms of middle-class cultural capital (Lareau, 2011). They meet 'multi-dimensional men' at university rather than the 'one-dimensional men' like themselves, who are constituted solely by meritocratic dispositions - hard work, determination, resilience and performance-orientated flexibility (Authors, 2018).

Exam performance became less important at university. You should have your own thoughts. We had group discussions in one course, which we did with Yuanpei College (an elite liberal arts college in Peking). Many of them (students at Yuanpei College) were top performers in Gaokao. We couldn't do anything but listen to them. I didn't know what they were talking about, Aristotle, Plato, etc., who I had never read before. 
Here the habitus dislocation experienced by our participants results in a 'self in crisis'. The exceptionality of our participants that is built on the high-achieving student self is endangered by meeting the middle-class high-achievers who are as smart, intelligent and hard-working as them but who are also capable in other areas of student life. Meanwhile, their sense of normality and inferiority as working class is intensified and heightened in their awareness of their deficiency in appropriate economic, cultural and social resources. They feel the gap between themselves and middle-class high-achievers, experience a sense of inadequacy, and realise their disadvantages in ways that had been obscure by their successes at school and, most importantly, experience a sense of fear, the fear of losing their 'high-achieving student identity', the only thing that makes sense of who they are, who they have become - and who they might be in the future. They need to protect themselves from this 'self in crisis', to reclaim their high-achieving student identity and to resume the balance in their habitus, to use the 'exceptionality' of the high-achieving student identity to salve the injuries associated with their working-class self.

Lacking the help, support and 'emotional capital' (Reay, 2005) that middle-class students acquire from their educated and confident parents, these young working-class people have only one strategy - the most realistic and effective strategy for them to deal with the 'self in crisis' and to achieve some kind of self-protection (Keane, 2011), that is to reemploy their meritocratic dispositions, as aptly described by Xiang He: 
After I became familiar with the life at this university, I worked at my utmost on my studies. In my whole university life, I had not stepped out the gate of the university more than eight times a year and this includes the times I went back home at vacations and I went out to have get-togethers with my classmates. I would not go out of the campus if I didn't have special reasons.

This sort of account was volunteered by many other participants. Jia Peng, for example, said, 'I stayed in the library almost every day of my first year at university. I went there at around 7 am or 8 am and went back at around $11 \mathrm{pm}$. It was like life at senior school'.

We are not suggesting that our respondents never attended social activities at university. Indeed, they all made attempts to attend student societies and some of them took leadership positions. However, for most of our participants (11 of 17 participants; the other six participants will be discussed elsewhere), their university life is overwhelmingly focused on academic performance.

Choosing to experience university this way is a decision based on deliberate thinking, careful evaluation and rational calculation, as Xiang He explains below:

This is a place where you can meet many excellent people, everywhere. You can feel the pressures every minute. However, it won't matter if you accept the fact. You do well, it's your business, nothing to do with me. If I have tried my best for my choice, I can be happy about myself. You can survive in this university without trying to jump from a building if you can comfort yourself with that thought. Only compare me with myself. It does not necessarily mean I can catch up with you, but it is good enough for me if I can keep moving forward. 
'Only compare me with myself' is setting double standards - as we are working class, we can expect less and we can achieve at lower standards. This is an adaptation to social disadvantage and the operation of working-class habitus, as Bourdieu (1990, p. 64) describes, 'adapting the economically most deprived to the specific condition of which they are the product'.

Yet, different from Bourdieu's emphasis on the unconscious operation of habitus - choices and calculations are made 'that can be objectively adapted to their outcomes without presupposing a conscious aiming at ends' (Bourdieu, 1990, p. 53), our participants' decision to 'only compare me with myself' is based on clear awareness of differences between them and middle-class students, of their different histories of capital accumulation, the excess of efforts they must expend, the 'impossibility' of being 'successful' in position-taking in the university social field and also, at least in part, the risks involved in choosing to devote themselves to achieving academic excellence - 'it doesn't mean I can catch up with you,' as mentioned by Xiang He in the above.

Archer (2010), Reay (2004) and Sayer (2005) all draw on Bourdieu's work but in such a way as to enable a place of reflexivity in understanding habitus. They argue that reflexivity, such as 'self-awareness and a propensity for self-improvement' (Reay, Crozier, \& Clayton, 2009, p. 1105) is generated at the disjunctures between habitus and field and that these disjunctures 'can generate change and transformation' (Reay, 2004, p. 436). Based on the analysis of our participants' responses to habitus dislocation, we argue that reflexive awareness is indeed generated at the disjunctures 
between habitus and field, but the reflexive responses of these students tend to ensure the consistency of rather than to introduce change and challenges to their old habitus.

As well as rational calculation, emotions are also involved in shaping our participants' reflexive responses to habitus dislocation. As argued by Reay (2005) and Sayer (2005), emotions are highly significant within unequal social relations and classed emotions contribute to the reproduction of inequalities. We have seen how much Yue Gu and Xiang He were struggling in the initial stage of their university life earlier in this section. Similar kinds of frustration, despair, loneliness and inferiority were mentioned by most of our participants. These emotions suggest that they are deeply hurt, especially given the enhanced sense of ambition, confidence and hope they bring with them from school to university. There is a big gap between their 'imagined future' (Ball, 2003; Ball, Macrae, \& Maguire, 2000) fostered and developed at school and the reality of university life. They need to accommodate the injuries and negative emotions that they experience, they need to grasp at something in order to survive these travails, to avoid the urge 'to jump from a building', but they know they have no other resources that they can only rely on but themselves and the dispositions that enabled them achieve at school and gain entry into this university. Compared with their accounts of school, the ways they describe working hard at university display little ambition, passion and expectation but rather are full of fears, compromises and despair. Some of them were very ambitious before arriving at university; as Da Tang explained, he had ambition to excel, 'to be better than others'. However these ambitions are undermined by the dislocations experienced at 
university, and ambition is tempered, as Yun Jiang puts it, 'do not always think of winning' and 'I couldn't win over others in every single way'.

These young people have to confront and accept their disadvantages and accept that working toward high performance is the only choice, the realistic way that is open to them, to 'the people like us'. Rationality, injuries and emotions fuse together, and reflexivity conspires with unconsciousness, in forming our participants' decision to make adaptations in relation to their deprivation. They come to recognise their disadvantage, their destiny, and the possibilities available to them, consciously and deliberately, which proves to be a greater misery, rather than unconsciously following the operation of working-class habitus.

\section{Success as double edged swords: reproduced as 'meritocratic agents' and reinforced symbolic domination of class}

On the one hand, our participants' strategy of re-investing in a commitment to meritocracy to deal with the 'self in crisis' is a reflexive response driven by their habitus; on the other hand, this perspective is a legitimate choice encouraged by the strong meritocratic emphasis at Chinese elite universities, if not as much as at Chinese schools. The strong meritocratic culture at Chinese elite universities, which constitutes another aspect of 'unusualness' in the context of China, can be seen from the enormous benefits our participants can mobilise by way of excellent exam performance. 
As Yue Gu illustrates in the account below, working on academic performance is a rational calculation based on the benefits she can 'enjoy' as a result. A very realistic return is generous scholarships, which can cover both tuition fees and living expenses. Considering other subsidies reported by our participants that they can access at university, like financial aid and on-campus part-time jobs, it is easy to understand why none of the participants in our study report economic difficulties at university. Since economic anxiety is the most direct and serious concern for these working-class high achievers, it is easy to understand why scholarships are such a tempting incentive, one that reinforces the meritocratic perspective, as Yue $\mathrm{Gu}$ comments, 'working hard on exam performance was mainly for earning scholarships'. Also, Yue Gu's account offers evidence for how strongly class influences them and drives them to continue to follow the meritocratic path of dependence on which they embarked at school.

I enjoyed the benefits of being high-achieving. I could have scholarships, pay tuition fees and live on my own and relieve my parents with less burdens to support me...Scholarships could cover all my costs at university, including tuition fees and living expenses and you could have some left over that you could use to socialise with friends...Yes. Working hard on exam performance was mainly for earning scholarships.

Apart from economic returns, some participants obtain non-economic returns, like a second chance at subject choices and switching to more popular subjects. This is very important for working-class students, particularly considering the random or ill-informed choices some of them make at the time of applying to university owing to 
a lack of 'hot knowledge' (Ball \& Vincent, 1998). Students at Chinese universities are allowed to switch to another subject after the first year, but the opportunity is normally restricted to the highest achieving students in each department. Among our participants, Zhen Liang changed his subject from environmental engineering to material science, which he learned could lead to better employment; Yuan Fang enrolled to study in a second bachelor's degree programme in finance from her second year given her excellent academic performance in her subject, psychology.

For Zhen Liang and Yuan Fang, excellent academic performance adds to their chances of gaining better employment, while for some other participants excellent academic performance can directly lead to better employment. For example, Xiang $\mathrm{He}$ and Yi Chen, both in the subject of electronic engineering, report a direct link between academic performance and their employment. According to them, employment in this industry requires a postgraduate degree and both of them were recommended to the postgraduate programme, which also waived tuition fees as a result of their excellent academic performance. The average annual salary for electronic engineers, as reported by the two participants, is around $180,000 \mathrm{RMB}$, which is more than twice the average salary in Shanghai $\left(71,268 \mathrm{RMB}\right.$ in $\left.2015^{3}\right)$. For the participants who are in subjects that link academic performance to employment, a meritocratic perspective is a very reasonable choice.

\footnotetext{
3 According to http://shzw.eastday.com/shzw/G/20160403/u1ai9280455.html (An official website of Shanghai Government); we use the data in 2015 as the average salary reported by these two participants was in 2015 when we had the second interview with them.
} 
A very unusual, non-economic return reported by our participants that can also come from their excellent performance is extra-credential experience, such as overseas travel and placements. Six participants in our study had experience of overseas studies or visits. Four of them earned the opportunity to study abroad based on their excellent academic performance; the other two gained the opportunity to visit an international university through a programme specifically aimed at working-class students. All these exchange programmes in which our participants participated are fully funded (including tuition fees and living expenses) by the university. Some studies (Lehmann, 2012) indicated the difficulties for working-class students to obtain valuable extra-curricular activities at university, especially studying abroad experiences, owing to the expensive costs of these programmes. The 'unusual' social achievements of our participants, different from those recorded in other studies, can be understood as the unusual context of Chinese elite universities that still has a major emphasis on meritocracy in its culture.

Furthermore, Hui Tang's account of her experience at Yale University adds to the understanding of the social accomplishments our participants achieve at university. She made no mention of socialising with her classmates or any other aspects of social life at Yale but only described the library and courses she took. Even at the overseas university, academic performance was still her main concern and her life was still focused solely on her studies. Again new experiences do not necessarily bring changes and transformations of the habitus but can be negotiated by habitus on its 'principle of continuity'- 'to refuse what is anyway denied and to will the 
inevitable' (Bourdieu, 1990, p. 54). Hui Tang held on to what is familiar and safe ensuring the 'constancy' of her habitus even when she was in a vastly different environment. Access to new experiences does not necessarily mean for these students changes of habitus and engaging in social behaviours that are typically restricted to middle-class students, they do not necessarily acquire 'middle-class social or cultural capital' (Aries \& Seider, 2005; Lehmann, 2013). They experience these experiences through and in relation to their habitus and reinforce the dispositions that provided the opportunities in the first place.

The strong meritocratic environment of Chinese elite universities has double-edged effects for the social mobility of working-class high-achievers. On the one hand, it provides them with many opportunities and possibilities to draw on dispositions they have already developed at school, to maintain a high-achieving student self, to access forms of new experience and to deal with hidden injuries arising from the sense of habitus dislocation. On the other hand, their socialisation at university reproduces these working-class high-achievers as 'meritocratic agents' and subjects of class domination. Their construction of particular sorts of university experience is a form of self-subjection ${ }^{4}$. We (2018) explore the major investment of working-class high-achievers in the meritocratic disciplines of their schooling. For these students their class capitals offer them only one choice - to accept meritocracy as a form of self-definition or to stay in the working class. We go on to argue that these working-class high-achievers do not transcend class domination but experience

\footnotetext{
${ }^{4}$ We are suggesting an extension here of Bourdieu's notion of self-exclusion (Bourdieu \& Passeron, 1990).
} 
another form of domination, which is mediated by meritocracy. As demonstrated in this paper, the socialisation of working-class students at elite universities does not transform but instead reinforce their habitus and their dispositions as "meritocratic agents' and correspondingly enhances the consequences of class domination and the risks they may confront in the future - 'cultural discontinuity' (Liu, Wang, \& Yang, 2012, p. 52) they may experience in the un-meritocratic labour market field. Yet, the risks working-class high-achievers are likely to confront in the future, after university, remain obscured in the meritocratic field of elite universities in China, and by the benefits, protections and successes they can obtain by deploying their meritocratic dispositions. The problem is that, the later they realise the on-going consequences of class domination, the harder these consequences are to rectify. This may partly explain why some of our respondents come to accept their relative disadvantages in the job market. At the time of making employment decisions, seven participants accepted 'whatever came to them' and four participants adopted a strategy of suspension $^{5}$, postponing their decisions by pursuing doctoral studies; only six participants made the 'active' choice to pursue a job in which they were interested. With all the years of training and discipline in the meritocratic environment, it is almost impossible for them to change who they are and who they might be - the only possibility is to make adaptations in relation to what they lack.

These working-class high-achievers' experience of university pushes them further in the direction determined by their class position, to rely on meritocracy, to

\footnotetext{
5 See the definition and meaning of suspension at https://www.compas.ox.ac.uk/event/suspension/.
} 
believe in meritocracy, to embrace and promote meritocracy and to be moulded as firm 'meritocratic agents' - hard-working, determined, self-responsible and instrumental. They are thus subject to the symbolic domination of class rather than escape it.

\section{Precarious success: survival by 'chance' and always being 'fish out of water'}

The risks embedded in the experiences of these young people at university are not only those of 'cultural discontinuity' they may confront in an un-meritocratic environment in the future, but also the unstable success of their meritocratic reflexive response in a meritocratic environment, within the university. In the absence of the right capitals these working-class survivors maintain an uncertain grasp on academic success. Even in a meritocratic environment in which they can bring to bear their accumulated relevant skills, ease and competencies as 'meritocratic agents', their success still cannot be assumed and guaranteed but may also depend on 'chance'. Chance appeared regularly in the students' accounts. The first kind of 'chance' is that of being in a subject field where meritocratic dispositions are directly related to excellent academic performance, and this is most evident in STEM subjects. For example, Ping Wang, who is studying naval engineering, and Xiang He, whose subject is electronic engineering, find it easier to maintain high-level academic performance than Shan Cui and Wei Luo, who are both in the subject of law, which requires more accumulation of middle-class cultural capital to achieve higher academic performance. The second kind of 'chance' means meeting important 
persons and having 'critical moments' during time at university. The 'critical moment' was coined by Yue Gu when she talked about her path of dependence on academic performance at university:

I was thinking of going to find a job after university. Then I was thinking I didn't have to work hard on studies. But I was so bored that I went to the tutorial class of mathematics. Then I got a good result on the final exam that term. That was a 'critical moment' for me. When you have that moment, you will think since I already got eighth place, it would be a shame if you don't work hard (to keep it). I think it's a path of dependence.

The 'chance' for Yue Gu is that she happened to attend the tutorial course and had the 'critical moment' that started her on what she calls 'a path of dependence'. Similarly, 'chance' is extremely important in Da Tang's story. The 'chance' for Da Tang is that he met a teacher on a course who was kind enough to give him extra tuition and to involve him in a research project, where he met postgraduates, gained research experience, contributed to publications and was then recommended to a postgraduate programme. Da Tang's university experience was altered from the point that he met this teacher. Before this 'critical moment' he was miserable and stuck in many kinds of dislocations, having difficulties in finding classrooms and struggling to follow computer classes, while after the 'critical moment' he slowly found the way to use the dispositions he developed at school and to make academic progress. It is worth noting that this encounter was not a matter of strategy and effort to accumulate social capital, which according to Bourdieu (1986) requires the investment of time, energy and planning; rather it is a 'chance', a lucky meeting with a kind teacher. In a large sense, 
'chance' saves Da Tang from the damage wrought by social and cultural dislocations and determines his survival.

The third kind of 'chance' is, as mentioned earlier in the examples of Xiang He and Yi Chen, 'ending up' in a subject that leads to good employment and high salaries. We refer to this as 'chance' because neither of the participants 'chose' this subject when they made university applications; rather, they 'happen' to end up in this subject. Yi Chen had no idea of what 'electronic engineering' was when he made university applications and his first choice was mechanical engineering as it was industry-orientated, known by everyone and can assure a job after university'. Only when he entered university, did he begin to understand the advantage of electronic engineering over mechanical engineering for his employment prospects. Three other participants in the study 'ended up' by chance in such 'shortage' subjects.

These working-class high-achievers reinvested in their meritocratic dispositions at university as a reflexive response to habitus dislocations. However such re-investment is risky, even in a strongly meritocratic environment. Think of the possibilities if Yue Gu missed the chance to attend the tutorial class, Da Tang did not meet the kind teacher and Xiang $\mathrm{He}$ and Yi Chen were not studying electronic engineering. There is no guarantee of success for working-class high-achievers; all they can do is to work hard and hold a last hope for 'chance'. Also, as indicated by Frank (2016), there are in the real world no meritocratic environments where chance and the uneven distribution of capitals do not matter and do not play a role in advantaging those who bring existing advantages with them. Therefore these 
'meritocratic agents' will always be rootless, living with uncertainty, anxiety, imaginary or real failures and the constant fear of being caught out and dragged back to the working-class destiny.

\section{Conclusion: habitus transformation as imaginaries, working-class survivors as atoms of meritocracy}

The elite university is often represented in the policy rhetoric as a place that can broaden working-class students' horizons, outlooks, experiences, perspectives, resources and life chances, and as suggested by some research a place that can bring about 'habitus transformation' for working-class students. This paper offers a different view of the university experience, as reinforcing rather than reforming class differences and social and cultural inequalities.

We go on to argue that this reinforcement is not simply driven by the unconscious operation of working-class habitus, as explained by Bourdieu, but involves a degree of consciousness and strategy in the making adaptations to disadvantage. This reinforcement rests on the decisions of working-class students to accept their disadvantages, their position, their history and their 'probable future' (Bourdieu, 1990, p.64), which is forged in the complex interplay of instrumental rationality, the hidden injuries of class, habitual dispositions, and the pursuit of a sense of security, over and against the threats to the high-achieving self that defines them, distinguishes them and has delivered them some sense of hope of upward social mobility. The choice to pursue and invest themselves and their identity in achieving 
high levels of academic performance at university, to manage university life by compartmentalising the social and the academic, is both a form of striving and surrender, it combines ambition with frustration, and moments of hope with others of despair. This is a choice, of sorts, for 'people like us', in many ways the only choice for a high-achieving working-class student. Working-class survivors do not escape from the position that is expected by their class position; rather they arrive to a position of exclusion via a different trajectory.

The working-class young people in our study experience class domination in the form of success, training and discipline, at school and at university. This is indicative perhaps of Foucault's explanation of the workings of disciplinary power, 'the chief function of the discipline is to "train", rather to select and to levy' (Foucault, 1977, p. 170). These young people are 'made' as subjects, as 'instruments of exercise' (Foucault, 1977, 170) by the disciplines of meritocracy at school and at university, by the rewards they can mobilise in these meritocratic environments, by their own rational choices and reflexive responses within these meritocratic settings and their practices of measurement and comparison. Our respondents, as described by Foucault, are 'no doubt the fictitious atom of an "ideological" representation of society', but are also 'a reality fabricated by this specific technology of power that I have called “discipline"” (1977, p. 194). As these working-class high-achievers are made as the atoms of meritocracy, the most hard-working, intelligent and ambitious of working-class students are caught in a position of 'social limbo', being isolated from both their origin and destination class (Friedman, 2016, p. 132). They are trained and 
transformed into 'meritocratic agents' and they contribute their intelligence and efforts to extending the disciplines of meritocracy, and, in new ways, to enhancing class inequality and domination. However, for these 'meritocratic agents' themselves, with no existence of a meritocratic environment in the real world, they will always be aliens, 'straddlers' (Lubrano, 2004) and hopeful but vulnerable chance-seekers.

Class profoundly shapes the way students experience university and other fields of education. Educational experiences, for working-class students are rarely liberating and transformative, the working-class habitus always haunts them and constrains them and consumes their new experiences, and the possibilities that arise of a different future. The production and reproduction of disadvantage begins on the day they begin the education journey, but the consequences of choices made, opportunities offered and rational planning may only become apparent much later.

\section{References}

Archer, L., \& Leathwood, C. (2003). Identities, inequalities and higher education. In L. Archer, M. Hutchings, \& A. Ross (Eds.), Higher education and social class: Issues of exclusion and inclusion (pp. 175-191). London: RoutledgeFalmer.

Archer, M. S. (2010). Conversations about reflexivity. London: Routledge.

Aries, E., \& Seider, M. (2005). The interactive relationship between class identity and the college experience: The case of lower income students. Qualitative Sociology, 28(4), 419-443. 
Authors. (2018). Questioning meritocracy: Findings from a life story study of working-class students at elite universities. Manuscript submitted for publication.

Ball, S. (2003). Class strategies and the education market: The middle classes and social advantage. London: Routledge.

Ball, S., Macrae, S., \& Maguire, M. (2000). Choice, pathways and transitions post-16: New youth, new economies in the global city. London: Routledge.

Ball, S., \& Vincent, C. (1998). 'I heard it on the grapevine': 'Hot' knowledge and school choice. British Journal of Sociology of Education, 19(3), 377-400.

Bathmaker, A-M., Ingram, N., \& Waller, R. (2013). Higher education, social class and the mobilisation of capitals: Recognising and playing the game. British Journal of Sociology of Education, 34(5-6), 723-743.

Bourdieu, P. (1986). Forms of capital. In J. Richardson (Ed.), Handbook of theory and research for the sociology of education (pp. 241-258). New York: Greenwood.

Bourdieu, P. (1990). The logic of practice. Cambridge, UK: Polity Press.

Bourdieu, P. (1996). The state nobility: Elite schools in the field of power. Cambridge, UK: Polity Press.

Bourdieu, P. (1999). The weight of the world: Social suffering in contemporary society. Cambridge, UK: Polity Press.

Bourdieu, P., \& Passeron, J. C. (1990). Reproduction in education, society and culture (2nd ed.). London: Sage. 
Bourdieu, P., \& Wacquant, L. D. (1992). An invitation to reflexive sociology. Chicago: University of Chicago Press.

Brown, P. (2009). Education, meritocracy and the global war for talent. Journal of Education Policy, 24(4), 377-392.

Charmaz, K. (2014). Constructing Grounded Theory (2nd ed.). Thousand Oaks, CA: Sage.

Foucault, M. (1977). Discipline and punish: The birth of the prison. New York: Vintage Books.

Frank, R. (2016). Success and luck: Good fortune and the myth of meritocracy. Princeton: Princeton University Press.

Friedman, S. (2016). Habitus clivé and the emotional imprint of social mobility. The Sociological Review, 64(1), 129-147.

Giroux, S. (1983). Theories of reproduction and resistance in the new sociology of education: A critical analysis. Harvard Educational Review, 53(3), 257-293.

Granfield, R. (1991). Making it by faking it: Working-class students in an elite academic environment. Journal of Contemporary Ethnography, 20(3), 331351.

Hurst, A. L. (2010). The burden of academic success: Loyalists, renegades, and double agents. Lanham: Lexington Books.

Jackson, B., \& Marsden, D. (1962). Education and the working class. Harmondsworth, UK: Pelican. 
Karabel, J. (2005). The chosen: The hidden history of admission and exclusion at Harvard, Yale and Princeton. Boston and New York: Houghton Miffen Company.

Keane, E. (2011). Distancing to self-protect: The perpetuation of inequality in higher education through socio-relational dis/engagement. British Journal of Sociology of Education, 32(3), 449-66.

Keane, E. (2015). Considering the practical implementation of constructivist grounded theory in a study of widening participation in Irish higher education. International Journal of Social Research Methodology, 18(4), 415-431.

Kipnis, A. (2001). The disturbing educational discipline of "peasants". The China Journal, (46), 1-24.

Lareau, A. (2011). Unequal childhoods: Class, race and family Life (2nd ed.). Berkeley: University of California Press.

Lawler, S. (1999). Getting out and getting away: Women's narratives of class mobility. Feminist Review, 63(Autumn), 3-24.

Lehmann, W. (2009). Becoming middle class: How working-class university students draw and transgress moral class boundaries. Sociology, 43(4), 631-647.

Lehmann, W. (2012). Extra-credential experiences and social closure: Working-class students at university. British Educational Research Journal, 38(2): 203-218.

Lehmann, W. (2013). Habitus transformation and hidden injuries: Successful working-class university students. Sociology of Education, 87(1), 1-15. 
Li, H. (2013). Rural students' experiences in a Chinese elite university: Capital, habitus and practices. British Journal of Sociology of Education, 34(5-06): $829-847$.

Liu, Y., Green, A., \& Pensiero, N. (2016). Expansion of higher education and inequality of opportunities: A cross-national analysis. Journal of Higher Education Policy and Management, 38(3), 242-263.

Liu, Y. S., Wang, Z. M., \& Yang, X. F. (2012). Selecting the elite: Status, geography and capital — admission of rural students into Peking University (1978-2005). International Journal of Chinese Education, 1(1), 19-53.

Lu, J. (2013). Shanghai Jichu Jiaoyu Gongping de Shizheng Yanjiu. [An empirical study on inequalities in basic education in Shanghai]. Jiaoyu Yanjiu, (2), $77-84$

Lu, X. Y. (2002). Dangdai Zhongguo Shehui Jie'ceng Yanjiu Baogao [A report on the social classes in contemporary China]. Beijing: Social Sciences Academic Press.

Lubrano, A. (2004). Limbo: Blue-collar roots, white-collar dreams. Hoboken, NJ: John Wiley \& Sons.

Marginson, S. (2011). Higher education in East Asia and Singapore: Rise of the Confucian model. Higher Education, 61(5), 587-611.

Reay, D. (2004). 'It's all becoming a habitus': Beyond the habitual use of habitus in educational research. British Journal of Sociology of Education, 25(4), 431444. 
Reay, D. (2005). Beyond consciousness?: The psychic landscape of social class. Sociology, 39(5), 911-928.

Reay, D., Crozier, G., \& Clayton, J. (2009). 'Strangers in Paradise'? Working-class students in elite universities. Sociology, 43(6), 1103-1121.

Reay, D., Crozier, G., \& Clayton, J. (2010). 'Fitting in' or 'standing out': Working-class students in UK higher education. British Educational Research Journal, 36(1), 107-124.

Reay, D., Hollingworth, S., Williams, K., Crozier, G., Jamieson, F., James, D., \& Beedell, P. (2007). 'A darker shade of pale?' Whiteness, the middle classes and multi-ethnic inner city schooling. Sociology, 41(6), 1041-1060.

Sayer, A. (2005). The moral significance of class. Cambridge, UK: Cambridge University Press.

Sennett, R., \& Cobb, J. (1972). The hidden injuries of class. Cambridge, UK: Cambridge University Press.

Shavit, Y., \& Blossfeld, H. (1993). Persistent inequality: Changing educational attainment in thirteen countries. New York: Avalon Publishing.

Skeggs, B. (1997). Formations of class and gender. London: Sage.

Stuber, J. (2011). Inside the college gates: How class and culture matter in higher education. Lanham: Lexington Books.

Thornberg, R. (2012). Informed grounded theory. Scandinavian Journal of Educational Research, 56(3), 243-259. 
Willis, P. (1977). Learning to labour: How working class kids get working class jobs. Westmead, UK: Saxon House.

Xiang, B., \& Wei, S. (2009). International student migration and social stratification in China. International Journal of Education Development, 29(5), 513-522.

Xie, A. L. (2016). Jingying Xuexiao zhong de Nongcunji Xuesheng: Shehui Liudong yu Shengcun Xintai de Zhuanbian. [Rural students in China's elite universities: Social mobility and habitus Transformation]. Jiaoyu Yanjiu, (11), 74-81. 